\title{
Secondary Stroke Prevention: Practice Patterns in a Tertiary Care Stroke Service
}

\author{
Janice C. Fan, Tania M. Mysak, Thomas J. Jeerakathil, Glen J. Pearson
}

\begin{abstract}
Background: Stroke and transient ischemic attack (TIA) have a high personal and financial cost to society and prevention is critical. Outside of registries in Ontario, there has been little effort to determine whether care gaps exist for secondary preventative care within Canada. The objective of this study was to evaluate inpatient medical team compliance to four secondary stroke prevention interventions: antithrombotic therapy, antihypertensive therapy, lipid lowering therapy and smoking cessation. Methods: Adults admitted to the University of Alberta Hospital stroke service with a diagnosis of stroke or TIA between August 1st, 2005 and July 31 st, 2006 were identified using International Classification of Diseases (10th Revision) codes. Two hundred charts were randomly selected for retrospective review. Compliance, defined as achievement of therapeutic targets or appropriate therapy for subtherapeutic targets, was assessed. Results: Among 190 eligible patients (mean age 67 years, $55 \%$ male), 147 (77.4\%) had a non-cardioembolic cerebral event while $43(22.6 \%)$ had a cardioembolic cerebral event. We found high compliance for antithrombotic (92\% [174/190]) and antihypertensive (95\% [136/143]) agents, but suboptimal compliance for lipid lowering agents (68\% [107/158]) and smoking cessation (27\% [17/64]). Conclusions: There is room for improvement in early risk factor management for secondary prevention, even in specialized stroke centres. To optimize stroke preventative care, more interdisciplinary collaboration, investigation of reasons for suboptimal care, development of strategies to minimize care gaps and ongoing stroke care audits for quality improvement are needed.
\end{abstract}

RÉSUMÉ: Prévention secondaire de l'accident vasculaire cérébral : modèles de pratique dans un service de soins tertiaires de l'accident vasculaire cérébral. Contexte : L'accident vasculaire cérébral (AVC) et l'ischémie cérébrale transitoire (ICT) comportent un coût personnel élevé et un coût financier élevé pour la société et leur prévention est très importante. Outre les registres de l'Ontario, peu d'efforts ont été faits pour déterminer s'il existe des lacunes au niveau des soins de prévention secondaire au Canada. L'objectif de cette étude était d'évaluer l'application de quatre interventions en prévention secondaire de l'AVC : la thérapie antithrombotique, la thérapie antihypertensive, le traitement de la dyslipidémie et l'arrêt du tabagisme. Méthodes : Les adultes hospitalisés au service d'AVC de l'University of Alberta Hospital pour un diagnostic d'AVC ou d'ICT entre le 1er août 2005 et le 31 juillet 2006 ont été identifiés au moyen des codes de la Classification internationale des maladies, 10e révision. Deux cent dossiers ont été choisis au hasard afin d'effectuer une revue rétrospective. Nous avons évalué l'observance définie comme l'atteinte des objectifs thérapeutiques ou le traitement approprié pour des cibles sous-thérapeutiques. Résultats : Cent quarante-sept $(77,4 \%)$ des 190 patients éligibles, dont l'âge moyen était de 67 ans et dont 55\% étaient des hommes, avaient eu un événement non cardioembolique alors que 43 (22,6\%) avaient subi un événement cardioembolique. L'observance en ce qui concerne les agents antithrombotiques (92\%, soit 174 des 190 patients) et les antihypertenseurs (95\%, soit 136 de 143 patients) était élevée, mais sous-optimale en ce qui concerne les agents hypolipidémiants (68\%, soit 107 de 158 patients) et l'arrêt du tabagisme (27\%, soit 17 de 64 patients). Conclusions : La gestion précoce des facteurs de risque devrait être améliorée en prévention secondaire, même dans les centres spécialisés en AVC. Une plus grande collaboration interdisciplinaire, l'évaluation des raisons sous-jacentes à des soins sous-optimaux, l'élaboration de stratégies destinées à minimiser les lacunes et la vérification continue des soins de l'AVC pour en améliorer la qualité sont nécessaires pour optimiser les soins en prévention de l'AVC.

Can. J. Neurol. Sci. 2010; 37: 245-251

Stroke from all causes is the fourth leading cause of death and the leading cause of long-term adult disability that burdens the Canadian health care system with costs for hospitalization, longterm care, rehabilitation, drug use and lost productivity. ${ }^{1}$ From $2000-2001$, the cost of all stroke was $\$ 2.8$ billion out of $\$ 176.4$ billion in total attributable costs of illness in Canada. ${ }^{2}$ Furthermore, the risk of stroke recurrence ranges from 5-20\% annually, depending on patient-specific risk factors. ${ }^{3,4}$ Therefore, secondary stroke prevention via antithrombotic therapy and management of risk factors is essential to patient care.

Randomized trials have shown relative risk reductions (RRR) of $15-38 \%$ in stroke recurrence when antiplatelet agents such as acetylsalicylic acid (ASA), dipyridamole, clopidogrel or
dipyridamole/ASA are compared to placebo. ${ }^{5-9}$ For patients with atrial fibrillation, anticoagulants are more effective (65\% RRR versus placebo) than antiplatelets (20\% RRR versus placebo). ${ }^{10-12}$

From the Pharmacy Department (JCF), North York General Hospital, Toronto, Ontario; Pharmacy Services (TMM), Alberta Health Services; Division of Neurology (TJJ), Division of Cardiology (GJP), Department of Medicine, University of Alberta, Edmonton, Alberta, Canada.

Received July 6, 2009. Final Revisions Submitted October 7, 2009.

Correspondence to: Janice Fan, North York General Hospital, Pharmacy Department, 4001 Leslie Street, Toronto, Ontario, M2K 1E1, Canada. 
Besides dipyridamole/ASA, other antiplatelet/anticoagulant combinations have not demonstrated benefit in secondary stroke prevention. ${ }^{11}$ Using a variety of antihypertensive medications to control blood pressure is also effective for secondary stroke prevention, demonstrating $25-40 \%$ RRR, therefore patientspecific antihypertensive therapy is recommended. ${ }^{12-14}$ In the absence of firm trial evidence, time to initiation of antihypertensive therapy after an acute event is controversial due to possible cerebral hypoperfusion that may worsen outcomes, so clinicians often delay antihypertensive therapy by five to ten days acutely after stroke or transient ischemic attack (TIA).${ }^{15}$ In regards to hyperlipidemia, HMG-CoA (3-hydroxy-3-methylglutaryl CoA) reductase inhibitors (statins) have reduced stroke recurrence significantly by $20-25 \%$ RRR in several randomized controlled trials, even in stroke or TIA patients without other cardiovascular conditions. ${ }^{16-20}$ Although ethical concerns have precluded randomized controlled trials of smoking cessation, the American Heart Association and the American Stroke Association (AHA/ASA) clinical practice guidelines for secondary stroke prevention recommend smoking cessation because many observational studies have found its consistent benefits. $^{12}$

Clinical practice guidelines are developed to assist with patient care decisions, but they have been poorly applied in practice due to situation-specific compliance barriers. ${ }^{21,22}$ Quality improvement programs may improve patient care, as evidenced by Get With the Guidelines (GWTG) - Stroke in the United States, a prospective, national stroke quality improvement program. ${ }^{23}$ In Canada, a recent study of tertiary care institutions participating in a national stroke registry revealed secondary stroke prevention care gaps, particularly in organized inpatient stroke care and warfarin use for atrial fibrillation. ${ }^{24}$ Studies at the University of Alberta Hospital (UAH) Stroke Prevention Clinic have already found that some risk factors are suboptimally controlled at one year of followup. ${ }^{25,26}$ However, no inpatient practice pattern studies for secondary stroke prevention have been conducted to evaluate regional stroke care. The objective of this study was to assess baseline inpatient medical team compliance to four secondary stroke prevention interventions: antithrombotic therapy, antihypertensive therapy, lipid lowering therapy and smoking cessation.

\section{MeTHODS}

This study was a descriptive, retrospective chart review completed at the UAH in Edmonton Alberta, Canada, a tertiary care hospital that serves 1.5 million people. ${ }^{25,26}$ Physicians refer patients to the UAH stroke service, where stroke and non-stroke specialty trained neurologists provide acute care, assess risk factors and treat accordingly. ${ }^{27}$ Once stabilized, patients are transferred back to the referring physicians or discharged home, to long-term care facilities, other hospitals or rehabilitation centres.

The resources and time constraints for the project (one investigator given approximately one month's time to collect all data) determined that it was feasible to review 200 charts which were selected at random. Patients $\geq 18$ years of age who were admitted to the UAH stroke service with a diagnosis of ischemic stroke or TIA between August 1st, 2005 and July 31st, 2006 were eligible for inclusion in the source population for the random sample. Patients were excluded if they were diagnosed with a neurological condition other than ischemic stroke or TIA, died during hospitalization, or participated in other stroke research studies during the study period.

University of Alberta Hospital Health Records staff generated a list of all eligible patients in terminal digit order according to International Statistical Classification of Diseases and Related Health Problems, 10th Revision, enhanced Canadian version (ICD-10-CA) codes (G45.9, I63.0, I63.1, I63.2, I63.3, I63.4, I63.5, I63.6, I63.8, I63.9, I64) ${ }^{28}$ To select charts randomly from all 606 eligible patients, the study investigator used a computerized random number generator to select a set of 200 unique numbers from 1 to $606 .{ }^{29}$ All eligible patients on the list were numbered in ascending order and charts that corresponded to the 200 randomly selected numbers were retrieved from UAH Health Records. The same study investigator reviewed the selected charts, using standardized data collection forms to record: patient demographics, admission and discharge dates, suspected date of stroke occurrence, allergies or intolerances, past medical conditions, diagnosis on admission to stroke service, medication regimens (plus rationale for use or lack of use) at point of discharge from the stroke service, the last five blood pressure (BP) measurements prior to discharge, fasting lipid panel, smoking status, international normalized ratio, liver function tests or creatine kinase (CK), hemoglobin, serum creatinine and potassium.

The primary outcomes were medical team compliance to four secondary stroke prevention interventions: antithrombotics, antihypertensive drugs, lipid lowering therapy and smoking cessation. Desired therapeutic targets and compliance (as defined below) were locally adapted from the 2006 AHA/ASA Stroke Prevention Guidelines (Appendix). ${ }^{12}$

Compliance was assessed using data at the point of patient discharge from the stroke service, when we could expect desired therapeutic targets to be achieved or interventions to be initiated. The average of the last five BP measurements and the last low density lipoprotein (LDL) result upon discharge were used to assess compliance to antihypertensive and lipid lowering therapy. The team was deemed compliant if the desired therapeutic target was achieved for the risk factor in question as per the adapted guidelines in the Appendix: indication-specific antithrombotic therapy, achievement of condition-specific target $\mathrm{BP}$, treatment to target $\mathrm{LDL}<2.5 \mathrm{mmol} / \mathrm{L}$ (the target at the time of this study) and any chart documentation of smoking cessation counselling or pharmacotherapy. Compliance also included initiation of appropriate additional therapy for patients at subtherapeutic targets, or if additional therapy was not initiated for patients at subtherapeutic targets due to exceptional circumstances: dementia, cognitive or oral intake status changes that limited therapeutic options, palliative status and patients leaving against medical advice. For antithrombotic use, drugspecific exceptional circumstances included systemic or intracranial bleeding and bioprosthetic rather than mechanical heart valves. In the latter situation, antiplatelet agents were accepted as compliant. By investigator consensus, length of stay of $\leq 10$ days was considered an exceptional circumstance for antihypertensive medications given lack of clear direction from guidelines on when antihypertensives are safe post ischemic 
stroke. ${ }^{12}$ Another exceptional circumstance was liver function tests or CK $>3 \mathrm{x}$ upper limit of normal, or length of stay $<1$ day for lipid lowering therapy (inadequate time to obtain fasting lipid panel). ${ }^{12}$ Antithrombotic use $\geq 2$ weeks after hemorrhagic transformation, intracranial hemorrhage or other bleeding was considered compliant as per reference guidelines used at the time. ${ }^{12}$ If the team failed to record a patient's lipid, hypertensive or smoking status, they were deemed non-compliant.

Inpatient hypertension was defined as any $\mathrm{BP}$ at $\geq$ ten days after admission that was above the AHA/ASA target for a particular patient depending on their other medical conditions (see Appendix). ${ }^{12}$ Inpatient hyperlipidemia was defined as an LDL level of $\geq 2.5 \mathrm{mmol} / \mathrm{L}$. Our AHA/ASA-based definitions of blood pressure and LDL targets were consistent with corresponding Canadian guidelines in effect at the time..$^{30,31}$

Microsoft Excel (Microsoft Corporation. Redmond, WA) descriptive statistic functions were used to analyze compliance data, reported as proportions (n, \%). We calculated 95\% confidence intervals (CI) for the proportions if block size was sufficient [i.e. if $n^{*} p$ or $n *(1-p)$ were both greater than five for any particular proportion]. Ethics approval was obtained from the University of Alberta Health Research Ethics Board. Patient consent was not required for this retrospective study.

\section{ReSUlts}

Two hundred inpatient charts were retrieved. Ten patients were subsequently excluded due to participation in other stroke research studies during this audit time frame. The achieved sample size was 190 patients. Baseline patient demographics are listed in Table 1.

\section{Antithrombotic Therapy}

Of the 147 patients with non-cardioembolic events, 144 (98\%) were attributed to non-specific or presumed atherosclerotic causes (Table 2). Practice patterns of antithrombotic use demonstrate ASA was the most commonly used antithrombotic agent used in non-cardioembolic stroke, followed by clopidogrel then dipyridamole/ASA (Table 3). Of interest, 46 non-cardioembolic events occurred in patients previously treated with ASA. The medical team used clopidogrel in 30 of those patients $(65 \%)$, followed by 8 dipyridamole/ASA (17\%), 4 ASA + clopidogrel (9\%), 2 ASA + dipyridamole/ASA (4\%), 1 ASA (2\%) and 1 no antithrombotic therapy (2\%).

Thirty-seven of the 43 cardioembolic events were caused by atrial fibrillation $(86 \%)$. Practice patterns indicate the majority $(30 / 37,81 \%)$ of patients with atrial fibrillation received warfarin, ASA or the combination of ASA + warfarin. Eight were treated with ASA alone due to intracranial bleeding (7/8) or dementia $(1 / 8)$. Three patients were classified as exceptional circumstances as they were not treated with antithrombotics due to palliative status (1/3) and intracranial bleeding (2/3).

Clopidogrel was the alternative antiplatelet used in all patients with ASA or dipyridamole/ ASA allergy or intolerance, irrespective of stroke etiology. Eight patients received no antithrombotic therapy, but documentation indicated this was due to intracerebral hemorrhage or palliative status.

Compliance to antithrombotic therapy for all causes of stroke or TIA was $92 \%$ (non-cardioembolic events $95 \%$ and cardioembolic events $79 \%$ ). Of the 16 cases where the team was deemed non-compliant, $12(71 \%)$ were due to the use of antiplatelet/anticoagulant combinations that had not been adequately studied for efficacy or safety. The remaining four included three patients where clopidogrel was used for atrial fibrillation and one patient with a mechanical prosthetic heart valve who received ASA.

\section{Antihypertensive Therapy}

Of the 143 patients with inpatient hypertension (mean BP 138/77 mmHg), $53(37 \%)$ had concomitant diabetes or chronic kidney disease (DM/CKD) and therefore their target BP was < $130 / 80 \mathrm{mmHg}$. In the remainder (90 [63\%]), the BP target was < 140/90 $\mathrm{mmHg}$. Among the DM/CKD patients, only 21 (40\%) achieved the target $\mathrm{BP}$ during their admission. Of the remaining $32 \mathrm{DM} / \mathrm{CKD}$ patients, only $11(34 \%)$ received additional antihypertensive therapy to control their suboptimal BP. In the 90 patients with a target BP of < 140/90 mmHg, 57 (63\%) of them achieved this target. Among the remaining 33 patients with suboptimal BP (i.e. > 140/90 mmHg), only 13 (39\%) received additional antihypertensive therapy. Overall, with consideration of the ten day period post stroke event in which blood pressure lowering to target was not mandatory (exceptional circumstance as discussed above), compliance to antihypertensive therapy was 95\% (Table 4).

\section{Lipid Lowering Therapy}

Of the patient sample, 19/190 had unknown lipid status and $30 / 190$ had no hyperlipidemia. Two other patients with stroke/TIA due to arterial dissection were excluded from the lipid lowering compliance assessment due to unproven benefits in that population. Of the remaining 139 patients who had documented hyperlipidemia, the mean LDL was $2.84 \mathrm{mmol} / \mathrm{L}$. Sixteen patients with known hyperlipidemia prior to admission had unknown target LDL achievement due to lack of fasting lipid panels during their admission and were categorized as noncompliant. Compliance to lipid lowering was $68 \%$ for 158 patients with inpatient hyperlipidemia or unknown lipid status (Table 4).

\section{Smoking Cessation}

Sixty-four of the 190 patients were categorized as either current smokers or had unknown smoking status (information was unclear from chart review). Compliance to smoking cessation interventions overall was $27 \%$ (Table 4). Compliance for confirmed current smokers (17/47) was also poor at $36 \%$.

\section{INTERPRETATION}

The UAH inpatient stroke service had excellent compliance to antithrombotic and antihypertensive therapy, but suboptimal lipid lowering and smoking cessation compliance. Most patients experienced non-cardioembolic stroke or TIA due to nonspecific atherosclerotic causes. However, ASA, the most economical first line antiplatelet option, was used $<60 \%$ of the time. Clopidogrel was a popular alternative to ASA for noncardioembolic events that occurred with ASA despite its relatively high cost. Dipyridamole/ASA was used infrequently 


\section{Appendix: Guidelines for secondary stroke prevention used as practice standards}

\begin{tabular}{|c|c|}
\hline \multicolumn{2}{|c|}{ Non-Cardioembolic Stroke/TIA } \\
\hline $\begin{array}{l}\text { Non-Specific or Presumed } \\
\text { Atherosclerotic Cause }\end{array}$ & $\begin{array}{l}\text { ASA } 50-325 \mathrm{mg} / \text { day, clopidogrel or dipyridamole/ASA } \\
\text { ASA }+ \text { clopidogrel not recommended }^{9,12} \\
\text { Clopidogrel }^{8,11,12} \text { If ASA allergy }\end{array}$ \\
\hline Arterial Dissection & Warfarin (target INR 2.0-3.0) or antiplatelet ${ }^{12}$ \\
\hline Hypercoagulable State & Warfarin (target INR 2.0-3.0) ${ }^{12}$ \\
\hline \multicolumn{2}{|l|}{ Cardioembolic Stroke/TIA } \\
\hline Atrial Fibrillation & $\begin{array}{l}\text { Warfarin (target INR } 2.0-3.0)^{10-12} \\
\text { ASA } 325 \mathrm{mg} / \text { day }^{10-12} \text { If unable to take warfarin } \\
\text { Add low dose ASA }{ }^{10-12} \text { with coronary artery disease }\end{array}$ \\
\hline Prosthetic Heart Valves* & $\begin{array}{l}\text { Warfarin (target INR 2.0-3.0) x } 3 \text { months }-1 \text { year }{ }^{12} \\
\text { With coronary artery disease or event on warfarin add low dose ASA }{ }^{12}\end{array}$ \\
\hline Patent foramen ovale & Antiplatelet $^{12}$ \\
\hline Hypertension & $\begin{array}{l}\text { Allow ten days to achieve target blood pressure }<140 / 90 \mathrm{mmHg}(<130 / 80 \mathrm{mmHg} \text { for } \\
\text { diabetes or chronic kidney disease patients) using any antihypertensive drug }\end{array}$ \\
\hline Hyperlipidemia & Statins recommended to target $\mathrm{LDL}<2.5 \mathrm{mmol} / \mathrm{L}^{12,30,31}$ \\
\hline Smoking Cessation & Encourage all smokers to quit smoking by any means ${ }^{12}$ \\
\hline
\end{tabular}

despite having demonstrated a greater RRR and ARR for stroke versus ASA compared to clopidogrel versus ASA.6-8 The AHA/ASA guidelines did not recommend switching antiplatelets for ASA-treated stroke patients because such patients have not been appropriately studied in clinical trials. No direct comparisons between these medications were available at the time of our study and the available guidelines stated that both clopidogrel and dipyridamole/ASA were safe compared to ASA alone. ${ }^{12}$ Reasons for the observed use of clopidogrel were unclear, but may reflect clinical trial data in which clopidogrel demonstrated a modest reduction in combined vascular endpoints compared to ASA. ${ }^{8}$ More recently, updated guidelines have recommended dipyridamole/ASA over ASA alone based on the ESPRIT trial and the ProFESS trial which demonstrated that clopidogrel and dipyridamole/ASA are very similar in reduction of stroke, myocardial infarction and death. ${ }^{7,32,33}$ Reasons for the limited use of dipyridamole/ASA in our patients are unknown, but may reflect the increased risk of headache and dizziness as a side effect to this agent. Whether the cost of a drug factored into the selection of antithrombotic medications was not explored. Costs of antiplatelet agents range from pennies to almost $\$ 100 \mathrm{a}$ month and drug coverage varies from province to province, so perceptions of relative antithrombotic benefit versus large variance in costs may have been a factor in drug selection.

Total warfarin use (alone or in combination) for cardioembolic events due to atrial fibrillation appeared low at $62 \%$. However, antithrombotic use was still deemed appropriate in all atrial fibrillation patients but four, where inappropriate combination therapy or clopidogrel was used. Of the remaining 11 patients that did not receive warfarin, 8 received ASA alone and 3 did not receive antithrombotic therapy due to exceptional circumstances.

Due to our arbitrary allowance of ten days time to initiation of antihypertensive medications for suboptimal blood pressure,

\section{Table 1: Baseline patient demographics}

\begin{tabular}{|c|c|}
\hline Patient Characteristic & $\mathbf{N}(\%)$ \\
\hline Male Gender & $104 / 190(54.7)$ \\
\hline Mean Age (Years) \pm Standard Deviation & $67.0 \pm 16.1$ \\
\hline Male & $66.4 \pm 16.5$ \\
\hline Female & $67.7 \pm 15.7$ \\
\hline $\begin{array}{l}\text { Mean Length of Stay (Days) } \pm \text { Standard } \\
\text { Deviation }\end{array}$ & $10.1 \pm 13.1$ \\
\hline Non-Cardioembolic Event & $147 / 190(77.4)$ \\
\hline Non-Cardioembolic Stroke & $118 / 147(80.3)$ \\
\hline Non-Cardioembolic TIA & $29 / 147(19.7)$ \\
\hline Cardioembolic Event & $43 / 190(22.6)$ \\
\hline Cardioembolic Stroke & $40 / 43(93.0)$ \\
\hline Cardioembolic TIA & $3 / 43(7.0)$ \\
\hline Hypertension & $143 / 190(75.3)$ \\
\hline Hyperlipidemia & $141 / 190(74.2)$ \\
\hline Current Smoker & $47 / 190(24.7)$ \\
\hline Non-smoker & $126 / 190(66.3)$ \\
\hline Atrial Fibrillation & $37 / 190(19.5)$ \\
\hline Coronary Artery Disease & $42 / 190(22.1)$ \\
\hline Diabetes Mellitus (DM) & $48 / 190(25.3)$ \\
\hline Type 1 & $2 / 48(4.2)$ \\
\hline Type 2 & $46 / 48(95.8)$ \\
\hline Chronic Kidney Disease (CKD) & $18 / 190(9.5)$ \\
\hline
\end{tabular}


Table 2: Antithrombotic compliance for all cause stroke/TIA

\begin{tabular}{|c|c|c|c|}
\hline $\begin{array}{l}\text { Stroke/TIA } \\
\text { Type }\end{array}$ & Cause of Stroke/TIA & $\begin{array}{c}\text { Total } \\
\text { Compliance } \\
\mathbf{N} \\
\end{array}$ & $\begin{array}{c}\text { Total } \\
\text { Compliance } \\
\%(95 \% \text { CI }) \\
\end{array}$ \\
\hline \multirow{4}{*}{$\begin{array}{c}\text { Non- } \\
\text { Cardioembolic } \\
(\mathrm{N}=147)\end{array}$} & $\begin{array}{l}\text { Non-Specific or } \\
\text { Presumed } \\
\text { Atherosclerotic } \\
(\mathrm{N}=144)\end{array}$ & $138 / 144$ & $\begin{array}{c}95.8(92.5 \\
99.1)\end{array}$ \\
\hline & $\begin{array}{c}\text { Arterial Dissection } \\
(\mathrm{N}=2)\end{array}$ & $1 / 2$ & $50(--)^{* *}$ \\
\hline & $\begin{array}{l}\text { Hypercoagulable State } \\
(\mathrm{N}=1)\end{array}$ & $1 / 1$ & $100(--)$ \\
\hline & Subtotal & $140 / 147$ & $\begin{array}{c}95.2(91.7 \\
98.7)\end{array}$ \\
\hline \multirow{4}{*}{$\begin{array}{l}\text { Cardioembolic } \\
\qquad(N=43)\end{array}$} & $\begin{array}{c}\text { Atrial Fibrillation }(\mathrm{N}= \\
37)\end{array}$ & $30 / 37$ & $\begin{array}{c}81.1(68.5 \\
93.7)\end{array}$ \\
\hline & $\begin{array}{l}\text { Prosthetic Heart Valve } \\
\qquad(\mathrm{N}=3)\end{array}$ & $2 / 3$ & $66.7(--)$ \\
\hline & $\begin{array}{l}\text { Patent Foramen Ovale } \\
\qquad(\mathrm{N}=3)\end{array}$ & $2 / 3$ & $66.7(--)$ \\
\hline & Subtotal & $34 / 43$ & $\begin{array}{c}9.1(66.9 \\
91.3) \\
\end{array}$ \\
\hline \multicolumn{2}{|c|}{ Total Antithrombotic Compliance } & $174 / 190$ & $\begin{array}{c}91.6(87.7 \\
95.5)\end{array}$ \\
\hline
\end{tabular}

*Considered compliant if patients with bioprosthetic heart valves received ASA versus warfarin; ** 95\% CI could not be calculated if the proportion was derived from a very small block size (see methods)

compliance to antihypertensive therapy appeared exceptionally high even though a quarter of the hypertensive patients did not achieve target BP nor receive additional antihypertensive therapy by ten days.

Compliance to the recommended LDL target was low, primarily because lipid status was not assessed by history or laboratory data (69\% of non-compliance) despite the presence of standard admission orders which included a fasting lipid panel. The rationale for not treating the remaining patients with suboptimal LDL was unclear from documentation, but may be multifactorial. For example, clinicians may be appropriately uncertain about the relative importance of lipid lowering therapy in cardioembolic stroke patients not specifically studied in stroke prevention trials. ${ }^{18}$ Additionally, the benefits of acute lipid lowering are unproven in stroke populations in contrast to proven benefits for patients with coronary syndromes. ${ }^{34}$

Low compliance to smoking cessation is especially concerning because barriers to smoking cessation counselling would be negligible during hospitalization. Although it is unlikely that almost half of the smokers received no encouragement to quit, there was no documentation that this interaction occurred. This not only highlights a limitation of our retrospective design, but also indicates documentation of interventions as an area for improvement.

Similar to results from previous outpatient studies, risk factor management for inpatients was suboptimal at the time of these audits, even in tertiary care institutions such as UAH with a high level of stroke expertise. ${ }^{24-26}$ Such comparable data may not be surprising given that they were obtained from the same tertiary
Table 3: Antithrombotic practice patterns

\begin{tabular}{l|c|c}
\hline Antithrombotic Therapy & $\begin{array}{c}\text { Non-Cardioembolic } \\
(\mathbf{N}=\mathbf{1 4 7}) \\
\mathbf{N}(\mathbf{\%})\end{array}$ & $\begin{array}{c}\text { Cardioembolic } \\
\mathbf{( N = 4 3 )} \\
\mathbf{N}(\mathbf{\%})\end{array}$ \\
\hline ASA & $84(57)$ & $12(28)$ \\
\hline Clopidogrel & $37(25)$ & $3(7)$ \\
\hline ASA-Dipyridamole & $9(6)$ & 0 \\
\hline ASA + Clopidogrel & $7(5)$ & 0 \\
\hline ASA + ASA-Dipyridamole & $2(1)$ & 0 \\
\hline Warfarin & $2(1)$ & $15(35)$ \\
\hline ASA + Warfarin & $1(1)$ & $1(21)$ \\
\hline Clopidogrel + Warfarin & 0 & $3(7)$ \\
\hline None & $5(3)$ &
\end{tabular}

Table 4: Antihypertensive, lipid lowering and smoking cessation compliance

\begin{tabular}{|c|c|c|}
\hline $\begin{array}{l}\text { Secondary Stroke Prevention Risk } \\
\text { Factor Assessed }\end{array}$ & $\mathbf{N}$ & $\%(95 \% \mathrm{CI})$ \\
\hline Total Antihypertensive Compliance & $136 / 143$ & $95.1(91.5,98.7)$ \\
\hline At Target BP & $78 / 136$ & $57.4(49.1,65.7)$ \\
\hline $\begin{array}{l}\text { Not At Target BP Additional } \\
\text { Antihypertensive }\end{array}$ & $24 / 136$ & $17.6(11.2,24.0)$ \\
\hline $\begin{array}{l}\text { No Additional Antihypertensive } \\
\text { For Suboptimal BP }\end{array}$ & $34 / 136$ & $25.0(17.7,32.3)$ \\
\hline $\begin{array}{l}\text { Total Antihypertensive Non- } \\
\text { Compliance }\end{array}$ & $7 / 143$ & $4.9(--)$ \\
\hline $\begin{array}{l}\text { No Additional Antihypertensive } \\
\text { For Suboptimal BP }\end{array}$ & $7 / 7$ & $100(--)$ \\
\hline Total Lipid Lowering Compliance & $107 / 158$ & $67.7(60.4,75.0)$ \\
\hline At Target LDL & $45 / 107$ & $42.1(32.7,51.4)$ \\
\hline $\begin{array}{l}\text { Not At Target LDL Added Lipid } \\
\text { Lowering }\end{array}$ & $46 / 107$ & $43.0(33.6,52.4)$ \\
\hline $\begin{array}{l}\text { No Additional Lipid Lowering For } \\
\text { Suboptimal LDL }\end{array}$ & $16 / 107$ & $15.0(8.2,21.7)$ \\
\hline $\begin{array}{l}\text { Total Lipid Lowering Non- } \\
\text { Compliance }\end{array}$ & $51 / 158$ & $32.3(25.0,39.6)$ \\
\hline $\begin{array}{l}\text { Unknown Target LDL } \\
\text { Achievement }\end{array}$ & $16 / 51$ & $31.4(18.7,44.1)$ \\
\hline $\begin{array}{l}\text { No Additional Lipid Lowering For } \\
\text { Suboptimal LDL }\end{array}$ & $16 / 51$ & $31.4(18.7,44.1)$ \\
\hline Unknown Lipid Status & $19 / 51$ & $37.2(23.9,50.5)$ \\
\hline Total Smoking Cessation Compliance & $17 / 64$ & $26.6(15.8,37.4)$ \\
\hline Patient Counselling & $10 / 17$ & $58.8(35.4,82.2)$ \\
\hline Nicotine Patch & $5 / 17$ & $29.4(--)$ \\
\hline $\begin{array}{l}\text { Patient Counselling + Nicotine } \\
\text { Patch }\end{array}$ & $2 / 17$ & $11.8(--)$ \\
\hline $\begin{array}{l}\text { Total Smoking Cessation Non- } \\
\text { Compliance }\end{array}$ & $47 / 64$ & $73.4(62.6,84.2)$ \\
\hline No Smoking Cessation Intervention & $30 / 47$ & $63.8(50.1,77.5)$ \\
\hline Unknown Smoking Status & $17 / 47$ & $36.2(22.5,49.9)$ \\
\hline
\end{tabular}

*Considered compliant under exceptional circumstances for blood pressure if: no additional antihypertensive for suboptimal BP when length of stay $\leq 10$ days; or if patients were palliative or discharged against medical advice. Similar exceptions allowed if antihyperlipidemics were not prescribed in patients with abnormal liver function tests/CK ( $>3 \mathrm{x}$ upper limit of normal) or if lipid panels were not drawn in those with one day length of stay (limited time for completion of fasting lipid panel). 
care centre. However, preventative strategies should be initiated for all inpatients with stroke or TIA as they are a 'captive audience' less challenged by patient compliance or by reliance on a referring physician to initiate therapy. In contrast, reasons for inpatient medical team non-compliance to secondary prevention measures may include: diversion of effort to acute medical and neurological problems, the inability of cognitively compromised patients to understand risks and benefits of stroke preventative interventions, medical team workload, or disagreement that preventative efforts should be instituted in the acute inpatient setting. We were unable to explore these reasons further in the current study.

Our baseline secondary stroke prevention care data also compared favourably to those from GWTG - Stroke with the exception of smoking cessation: 96\% (GWTG) versus 92\% (UAH) for discharge antithrombotics, 74\% (GWTG) versus 68\% (UAH) for lipid lowering therapy and 65\% (GWTG) versus $27 \%$ (UAH) for smoking cessation. ${ }^{23}$ However, our definition of noncompliance as including those patient charts in which smoking cessation was not documented may have disadvantaged our medical team's performance relative to GWTG where only performance in the subset of confirmed smokers was examined. For all 790 United States hospitals that participated in GWTG Stroke, adherence to acute and secondary prevention stroke care performance measures increased significantly from 2003 to 2007, regardless of hospital size, teaching status or geography. ${ }^{23}$ Given the 1.18 yearly adjusted odds ratio of adherence to stroke care performance measures in GWTG - Stroke, the development of similar quality improvement programs in our region could improve secondary stroke prevention care and save substantial health care costs. ${ }^{23}$ Initial evidence-based strategies to improve stroke care include better use of pre-printed care orders to achieve lipid lowering and smoking cessation targets. ${ }^{35}$ Specific reasons for medical team non-compliance, where the risk factor is known and no obvious contraindications exist, should be investigated to develop stroke care improvement strategies. Some redundancies in stroke preventative care may be considered given the often daunting workload of medical team members. Using the expertise of other health care professionals with potentially overlapping scopes of practice may help optimize patient use of secondary stroke prevention therapies by reinforcing risk factor management through patient education, documentation of relevant interventions, or prescribing medications as legislation allows. ${ }^{36}$

Strengths of this retrospective chart review include standardized collection of detailed pharmacotherapy data by a single reviewer and random chart selection. However, several limitations of this design must be acknowledged. Our data only reflect what was documented in charts, so any discrepancies in documentation would directly affect the accuracy of our conclusions. Furthermore, these results may not be generalizable to other tertiary care centres. We were also unable to assess whether care by stroke or non-stroke specialty trained neurologists resulted in different levels of compliance. Whether patients achieved their therapeutic targets after discharge from the inpatient stroke service was another unknown, which may be particularly relevant when assessing best practice for lipid lowering therapy, as acute treatment of lipids is unproven in stroke patients. Our study size was relatively small but for most parameters the $95 \%$ confidence intervals suggested that the sample size was adequate to produce robust estimates, particularly for the total compliance measures in each category. Given the relatively small number of charts reviewed, selection bias may be present although we tried to minimize this systematically by randomly selecting charts for review. Finally, although the AHA/ASA guidelines were published after part of the data collection period, we were confident that these guidelines could be used as a benchmark for evidence-based practice because the neurologists at UAH were familiar with ongoing stroke research.

\section{Conclusions}

Optimizing secondary stroke prevention must be made a priority given the burden of stroke to the Canadian health-care system. Future research on explanations for non-compliance to secondary stroke prevention guidelines and development of quality improvement programs are needed to improve stroke preventative care. Additional solutions include more interdisciplinary reinforcement of risk factor management and repeated audits of stroke care performance in different practice settings for ongoing assessment and quality improvement.

\section{ACKNOWLEDGEMENTS (with affiliations at the time of this study)}

The authors would like to acknowledge the following individuals for their contribution to the initiation of this study: Christine Hughes, BSc Pharm, Pharm D, Faculty of Pharmacy and Pharmaceutical Sciences, University of Alberta, Edmonton, Alberta, Canada; Elizabeth Kozyra, BSc, BSc Pharm, Pharm D, Royal Alexandra Hospital, Capital Health, Edmonton, Alberta, Canada.

\section{REFERENCES}

1. Stroke statistics. Ottawa $(\mathrm{ON})$ : Heart and Stroke Foundation of Canada; [no date, cited April 10th, 2008]. Available from: http://www.heartandstroke.ab.ca/site/c.lqIRL1PJJtH/b.3651251/ k.BD66/stroke_statistics.htm.

2. Canadian Institute for Health Information. The burden of neurological diseases, disorders and injuries in Canada. Ottawa (ON): CIHI; 2007.

3. Coull AJ, Lovett JK, Rothwell PM. Population based study of early risk of stroke after transient ischaemic attack or minor stroke: implications for public education and organisation of services. BMJ. 2004;328:326.

4. Vickrey BG, Rector TS, Wickstrom SL, Guzy PM, Sloss EM, Gorelick PB, et al. Occurrence of secondary ischemic events among persons with atherosclerotic vascular disease. Stroke. 2002;33:901-6.

5. Antithrombotic Trialists' Collaboration. Collaborative metaanalysis of randomised trials of antiplatelet therapy for prevention of death, myocardial infarction, and stroke in high risk patients. BMJ. 2002;324:71-86.

6. Diener HC, Cunha L, Forbes C, Sivenius J, Smets P, Lowenthal A. European Stroke Prevention Study 2. Dipyridamole and acetylsalicylic acid in the secondary prevention of stroke. J Neurol Sci. 1996;143:1-13.

7. The ESPRIT Study Group. Aspirin plus dipyridamole versus aspirin alone after cerebral ischaemia of arterial origin (ESPRIT): randomised controlled trial. Lancet. 2006;367:1665-73.

8. CAPRIE Steering Committee. A randomised, blinded, trial of clopidogrel versus aspirin in patients at risk of ischaemic events (CAPRIE). Lancet. 1996;348:1329-39. 
9. Diener HC, Bogousslavsky J, Brass LM, Cimminiello C, Csiba L, Kaste M, et al. Aspirin and clopidogrel compared with clopidogrel alone after recent ischaemic stroke or transient ischaemic attack in high-risk patients (MATCH): randomised, double-blind, placebo-controlled trial. Lancet. 2004;364:331-7.

10. EAFT (European Atrial Fibrillation Trial) Study Group. Secondary prevention in non-rheumatic atrial fibrillation after transient ischaemic attack or minor stroke. Lancet. 1993;342:1255-62.

11. Albers GW, Amarenco P, Easton JD, Sacco RL, Teal P. Antithrombotic and thrombolytic therapy for ischemic stroke. Chest. 2004;126(3)Suppl:S483S-512.

12. Sacco RL, Adams R, Albers G, Alberts MJ, Benavente O, Furie K, et al. Guidelines for the prevention of stroke in patients with ischemic stroke or transient ischemic attack: a statement for healthcare professionals from the American Heart Association/ American Stroke Association Council on Stroke: co-sponsored by the Council on Cardiovascular Radiology and Intervention: the American Academy of Neurology affirms the value of this guideline. Stroke. 2006;37:577-617.

13. PROGRESS Collaborative Group. Randomised trial of a perindopril-based blood-pressure-lowering regimen among 6105 individuals with previous stroke or transient ischaemic attack. Lancet. 2001;358:1033-41

14. Rashid P, Leonardi-Bee J, Bath P. Blood pressure reduction and secondary prevention of stroke and other vascular events: a systematic review. Stroke. 2003;34:2741-9.

15. Semplicini A, Calo L. Administering antihypertensive drugs after acute ischemic stroke: timing is everything. CMAJ. 2005;172(5): 625-6.

16. The Long-Term Intervention with Pravastatin in Ischaemic Disease (LIPID) Study Group. Prevention of cardiovascular events and death with pravastatin in patients with coronary heart disease and a broad range of initial cholesterol levels. N Engl J Med. 1998; 339(19):1349-57.

17. Plehn JF, Davis BR, Sacks FM, Rouleau JL, Pfeffer MA, Bernstein $\mathrm{V}$, et al. Reduction of stroke incidence after myocardial infarction with pravastatin: the Cholesterol and Recurrent Events (CARE) study. Circulation. 1999;99:216-23.

18. The Stroke Prevention by Aggressive Reduction in Cholesterol Levels (SPARCL) Investigators. High-dose atorvastatin after stroke or transient ischemic attack. N Engl J Med. 2006;355 (6):549-59.

19. Law MR, Wald NJ, Rudnicka AR. Quantifying effect of statins on low density lipoprotein cholesterol, ischaemic heart disease, and stroke: systematic review and meta-analysis. BMJ. 2003;326: 1423-7.

20. Cholesterol Treatment Trialists' (CTT) Collaborators. Efficacy and safety of cholesterol-lowering treatment: prospective metaanalysis of data from 90056 participants in 14 randomised trials of statins. Lancet. 2005;366:1267-78.

21. Graham ID, Beardall S, Carter AO, Glennie J, Hébert PC, Tetroe $\mathrm{JM}$, et al. What is the quality of drug therapy clinical practice guidelines in Canada? CMAJ. 2001;165(2):157-63.

22. Cabana MD, Rand CS, Powe NR, Wu AW, Wilson MH, Abboud $\mathrm{PC}$, et al. Why don't physicians follow clinical practice guidelines? A framework for improvement. JAMA. 1999;282: 1458-65.

23. Schwamm LH, Fonarow GC, Reeves MJ, Pan W, Frankel MR, Smith EE, et al. Get With the Guidelines Stroke is associated with sustained improvement in care for patients hospitalized with acute stroke or transient ischemic attack. Circulation. 2009; $119: 107-15$.
24. Kapral MK, Laupacis A, Phillips SJ, Silver FL, Hill MD, Fang J, et al. Stroke care delivery in institutions participating in the Registry of the Canadian Stroke Network. Stroke. 2004;35: 1756-62.

25. Mouradian MS, Majumdar SR, Senthilselvan A, Khan K, Shuaib A. How well are hypertension, hyperlipidemia, diabetes, and smoking managed after a stroke or transient ischemic attack? Stroke. 2002;33:1656-9.

26. Mouradian MS, Hussain MS, Lari H, Salam A, Senthilselvan A, Dean $\mathrm{N}$, et al. The impact of a stroke prevention clinic in diagnosing modifiable risk factors for stroke. Can J Neurol Sci. 2005;32:496-500.

27. Capital Health programs and services: acute stroke. Edmonton (AB): Capital Health; [no date, cited December 15th, 2006]. Available from: www.capitalhealth.ca/ProgramsAndServices/ BrowseServicesByAlpha/Content?IA_ID=5988.

28. International Statistical Classification of Diseases and Related Health Problems, 10th Revision, enhanced Canadian version (ICD-10-CA). Ottawa (ON): Canadian Institute of Health Information; [no date; cited January 5th, 2007]. Available from: $\mathrm{http}: / /$ secure.cihi.ca/cihiweb/dispPage.jsp?cw_page=codingclass icd10_e.

29. Research Randomizer. Middletown (CT): Urbaniak GC, Plous S; [no date; cited March 4th, 2007]. Available from: www.randomizer.org/form.htm.

30. Canadian Hypertension Education Program recommendations for the management of hypertension 2006. Ottawa (ON): Canadian Hypertension Education Program; [no date, cited October 25th, 2006]. Available from: www.hypertension.ca.

31. Genest J, Frohlich J, Fodor G, McPherson R. Recommendations for the management of dyslipidemia and the prevention of cardiovascular disease: summary of the 2003 update. CMAJ. 2003;169(9):921-4.

32. Adams RJ, Albers G, Alberts MJ, Benavente O, Furie K, Goldstein $\mathrm{LB}$, et al. Update to the AHA/ASA recommendations for the prevention of stroke in patients with stroke and transient ischemic attack. Stroke. 2008;39:1647-52.

33. Diener HC, Sacco RL, Yusuf S, Cotton D, Ôunpuu S, Lawton WA, et al. Effects of aspirin plus extended-release dipyridamole versus clopidogrel and telmisartan on disability and cognitive function after recurrent stroke in patients with ischaemic stroke in the Prevention Regimen for Effectively Avoiding Second Strokes (PRoFESS) trial: a double-blind, active and placebocontrolled study. Lancet Neurol. 2008;7:875-84.

34. Cannon CP, Braunwald E, McCabe CH, Rader DJ, Rouleau JL, Belder R. Intensive versus moderate lipid lowering with statins after acute coronary syndromes. New Engl J Med. 2004;350: 1495-504.

35. California Acute Stroke Pilot Registry (CASPR) Investigators. The impact of standardized stroke orders on adherence to best practices. Neurology. 2005;65:360-5.

36. Ovbiagele B, Saver JL, Fredieu A, Suzuki S, McNair N, Dandekar A, et al. PROTECT: a coordinated stroke treatment program to prevent recurrent thromboembolic events. Neurology. 2004;63: 1217-22. 